\title{
Analisis Efektivitas Waktu Evakuasi pada Shelter Terminal 3 Skytrain (Kereta Layang) Bandara Internasional Soekarno-Hatta
}

\section{Analysis of the Effectiveness of the Evacuation Time at Terminal 3 Shelter Skytrain (Elevated Train) Soekarno-Hatta International Airport}

\author{
Handoko ${ }^{1}$, Destiana Sasqiya Putri ${ }^{2}$, Dhina Setyo Oktaria ${ }^{3}$ \\ handoko@ppi.ac.id,dhina@ppi.ac.id,destiana@ppi.ac.id
}

Politeknik Perkeretaapian Indonesia

\begin{abstract}
ABSTRAK
Tujuan dari penelitian ini adalah menganalisis alur evakuasi penumpang di shelter teminal 3 skytrain dan mengetahui kapasitas penumpang di shelter terminal 3. Bandara Soekarno Hatta memiliki 4 terminal, diantara keempat terminal di bandara ini terdapat terminal yang memiliki tingkat mobilitas penumpang yang dikategorikan cukup padat. Sehingga dalam pelaksaannya akan muncul berbagai macam kendala yang mungkin terjadi. Salah satunya ialah terjadi kecelakaan saat pengoperasian. Sehingga dibutuhkannya proses evakuasi yang sesuai dengan aturan evakuasi. Hal tersebut juga mengakibatkan diperlukannya pedoman dalam melakukan proses evakuasi seperti seberapa lama waktu yang dibutuhkan untuk proses evakuasi tersebut. Metode penelitian ini menggunakan pendekatan deskriptif kuanlitatif. Hasil penelitian dapat disimpulkan bahwa efektivitas waktu evakuasi yang dibutuhkan dari area platform menuju concourse sudah memenuhi standar. Hanya saja waktu efektivitas evakuasi dari area platform menuju area aman belum memenuhi karena melebihi standar dengan waktu sebesar 7,36 menit waktu real dilapangan.
\end{abstract}

Kata kunci: waktu evakuasi; jarak area; luas area; kecepatan orang berjalan; jumlah penumpang

\begin{abstract}
The purpose of this study was to analyze the passenger evacuation in the 3 skytrain terminal shelter and to determine the passenger capacity at the terminal shelter. Among the four terminals at this airport there are terminals that have a level of passenger mobility which is categorized quite dense. So that the implementation will appear various kinds of obstacles that may occur. One of them is an accident during operation. So the need for an evacuation process in accordance with the evacuation rules. It also resulted in the need for guidelines in conducting the evacuation process such as how long it would take for the evacuation process. This research method uses quantitative descriptive approach. The results of the study concluded that the effectiveness of the evacuation time required from the platform area to the concourse had met the standard. It's just that the effectiveness of the evacuation from the platform to the safe area has not met because it exceeds the standard with a time of 7.36 minutes real time in the field.
\end{abstract}

Keywords: evacuation time; area distance; area; walking speed; number of passengers 


\section{PENDAHULUAN}

Skytrain dikenal dengan kereta layang Bandara Internasional Soekarno Hatta merupakan moda transportasi dengan menggunakan sistem Automated Guideway Transit yang pertama di Indonesia khususnya di Bandara Internasional Soekarno-Hatta, Tangerang. Sejak dioperasikan 17 September 2017 oleh President Directure Angkasa Pura II Muhammad Awaluddin, kereta layang dengan lintas yang disediakan sepanjang 3,05 kilometer Automated People Mover System (APMS) berfungsi untuk menghubungkan Terminal 1, 2, dan 3 dengan dual track (Track A dan Track B). Skytrain membutuhkan waktu 5 menit dari satu terminal ke terminal lainnya, dan 7 menit diperlukan untuk mencapai dari Terminal 2 ke Terminal 3. Skytrain semakin diminati penumpang sebagai pilihan moda transportasi antarterminal yang memudahkan penumpang untuk mobilisasi dilain sisi karena gratis. Meskipun Skytrain dirancang sebagai sistem otomatis tanpa awak, layanan antar-jemput skytrain namun untuk saat ini masih dioperasikan oleh kru.

Sistem ini menggunakan metro-tyred metro yang digerakkan oleh bandara yang diproduksi oleh perusahaan milik negara PT.LEN Industri bekerja sama dengan Woojin Industri Korea Selatan. Tiga unit kereta beroperasi dengan masingmasing trainset yang terdiri dari 2 kereta. Mereka mampu mengangkut 176 penumpang dalam satu perjalanan. Kereta berjalan dengan kecepatan 30 kilometer per jam.

Ada 4 terminal yang dilayani oleh Airport Skytrain; Terminal 1 (T1), 2 (T2) dan 3 (T3) dan memiliki satu terminal kereta bandara (TIB). Skytrain terintegrasi ke stasiun kereta Soekarno Hatta International Airport (SHIA), dimana para penumpang dapat dengan mudah melakukan perjalanan ke - dan dari - pusat kota Jakarta dengan Link Rail Bandara Soekarno - Hatta.

Emergency Exit merupakan salah satu fasilitas keamanan yang sangat penting, karena ketika terjadi keadaan darurat pada suatu terminal (sebutan stasiun pada skytrain), terutama pada stasiun layang yang memiliki beberapa tingkat atau lantai, maka hal pertama yang dilakukan untuk evakuasi adalah berlari keluar dari stasiun. Proses keluar dari suatu stasiun ketika terjadi kondisi darurat merupakan salah satu faktor utama untuk menyelamatkan diri ketika berada di dalam jiwa akibat kebakaran atau kondisi darurat lainnya. Salah satu persyaratan bahwa dalam suatu bangunan termasuk stasiun yang mempunyai tingkat penumpang tinggi dan dianggap aman adalah adanya prasarana "Emergency Exit" yang dapat menjamin adanya kemudahan evakuasi penghuninya saat terjadi kondisi darurat. Pengertian kemudahan evakuasi disini adalah kecepatan evakuasi yang sesuai standar.

Menurut penelitian Andi Haris Muhammad (2017) mengemukakan bahwa waktu evakuasi adalah waktu total yang diperlukan untuk semua penumpang tiba di titik akhir evakuasi (master station). Kecepatan awal pergerakan orang pada setiap jalur evakuasi dianggap sama dengan kecepatan pada saat melewati lokasi jalur evakuasi sebelumnya. Pergerakan orang selama berada pada jalur evakuasi, khususnya lebar jalur. Ketika kepadatan pada satu ruang tertentu sudah melebihi kapasitas maksimum ruangan tersebut, dianggap tidak ada lagi perpindahan orang ke ruangan tersebut. Dengan demikian kecepatan pergerakan orang pada ruangan sebelumnya sama dengan nol.

Hasil penelitian Riska mengemukakan bahwa waktu efektivitas evakuasi di stasiun layang yang disesuaikan dengan NFPA 130 (National Fire Protection Assosiation) yaitu Standart for Fixed Guideway Transit anda Passeger Rail Systems 2014. Waktu tersebut dikaitkan dengan kondisi darurat yang terjadi di stasiun maupun di kereta saat pengoperasian. Hasil penelitian Nnurhadi (2017) mengemukakan bahwa waktu evakuasi penumpang di kapal dengan membandingkan antara kedua metode SimplifiedAnalysis.

Berdasarkan hasil kajian studi sebelumnya dan latar belakang tersebut diatas, penulis Berdasarkan hal-hal tersebut di atas, tujuan penelitian adalah untuk menganalisis alur evakuasi penumpang di shelter teminal 3 skytrain dan untuk mengetahui kapasitas penumpang di shelter terminal 3 .

\section{METODE PENELITIAN}

Penelitian ini menggunakan deskriptif kualitatif. Berdasarkan Sugiyo (2014) menyatakan bahwa penelitian kualitatif dengan menggunakan procedure penelitian yaitu pengumpulan data, reduksi data, penyajian data dan penarikan kesimpulan. Penelitian kualitatif 
adalah memahami fenomena apa yan di alami subjek penelitian dengan memanfaatkan berbagai metode alamiah. Perolehan data di dapat dariwawancara mendalam kepada 10 pegawai di statsiun sky train dan manajer yang bertugas di terminal 3, pengamatan dilokasi penelitian, dan pemanfaatan dokumen sekunder dari manajer yang bertugas di terminal 3. Dalam metode pengumpulan data, penulis menggunakan dua metode yaitu metode secara tidak langsung (data sekunder) dan secara langsung (data primer) yang pemanfaatannya berkaitan dengan proses perencanaan survei dan analisis permasalahannya.

\section{HASIL DAN PEMBAHASAN}

Shelter Terminal 3 Bandara merupakan salah satu jenis stasiun layang atau elevated berlokasi pada sisi timur-utara bandara Terminal 1 dan 2 dibangun dengan penggabungan arsitektur lokal dalam rancangannya, namun pada terminal 3 dibangun dengan desain modern kontemporer dengan ramah lingkungan dan rasa tradisional. Saat ini terminal 3 merupakan rumah bagi penerbangan domestik Garuda Indonesia hinggan penyelesaian lanjutan dimana semua penerbangan internasional (kecuali budget carrier) akan berpindah pula kesini. Berdasarkan Detail Engineering Design (DED) Shelter APMS Terminal 3 memiliki panjang lintasan $\pm 1,6 \mathrm{~km}$.

Berdasarkan Peraturan Menteri Perhubungan Nomor 48 Tahun 2015 tentang Standar Pelayanan Minimum Angkutan Orang dengan Kereta Api. Standar pelayanan minimum menjadi tolak ukur minimum pelayanan yang harus dipenuhi oleh penyedia layanan dalam memberikan pelayanan kepada pengguna jasa, yang harus dilengkapi dan dipergunakan sebagai pedoman penyelenggaraan pelayanan dan acuan penilaian kualitas pelayanan sebagai kewajiban dan janji penyedia layanan kepada masyaralat dalam rangka pelayanan yang berkualitas, cepat, mudah, terjangkau dan terukur.

Berdasarkan poin keselamatan mengenai informasi ketersediaan dan peralatan penyelamatan darurat dalam bahaya (kebakaran kecelakaan atau bencana alam) di Skytrain, pemenuhan fasilitas keselamatan seperti alat pemadam api ringan, hydrant dan informasi kontak darurat sudah tersedia. Seperti APAR (Alat Pemadan Api Ringan) sudah disediakan disetiap sudut Shelter Terminal 3. Diantaranya diletakkan di ujung ataupun tengah tiang tiap shelter, dan di bawah kursi tunggu penumpang. Terdapat total 18 APAR yang tersedia pada shelter terminal 3.

Kontak darurat yang disediakan oleh PT. Angkasa Pura II guna untuk komunikasi ketika terjadi kondisi darurat di shelter ialah dengan menyediakan tombol intercomeyang terhubung langsung ke ruang OCC (Operating Control Center).

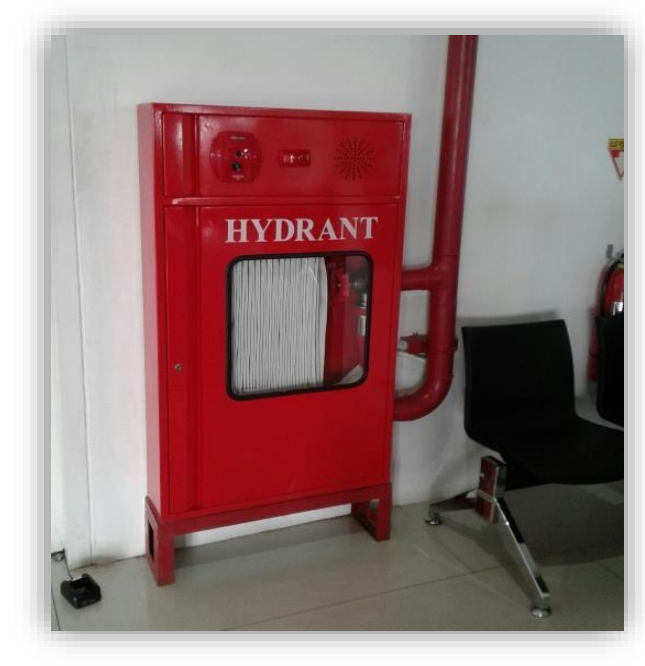

Gambar 1. Hydrant

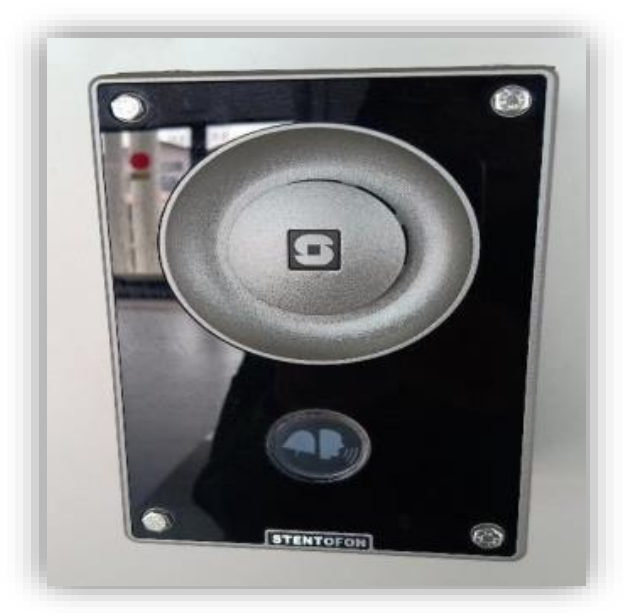

Gambar 2. Tombol Intercome

Berdasarkan poin informasi dan fasilitas kesehatan yang ada di Shelter Terminal 3 terdapat fasilitas kesehatan seperti kursi roda dengan tujuan agar penumpang yang membutuhkan mampu teratasi secara baik. 


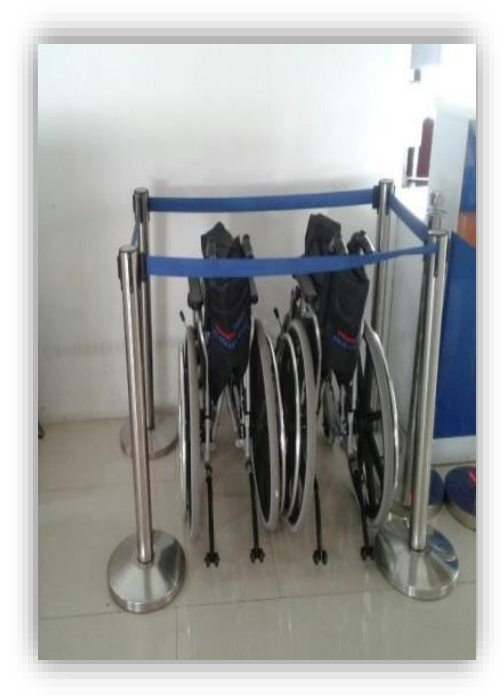

Gambar 3. Kursi Roda

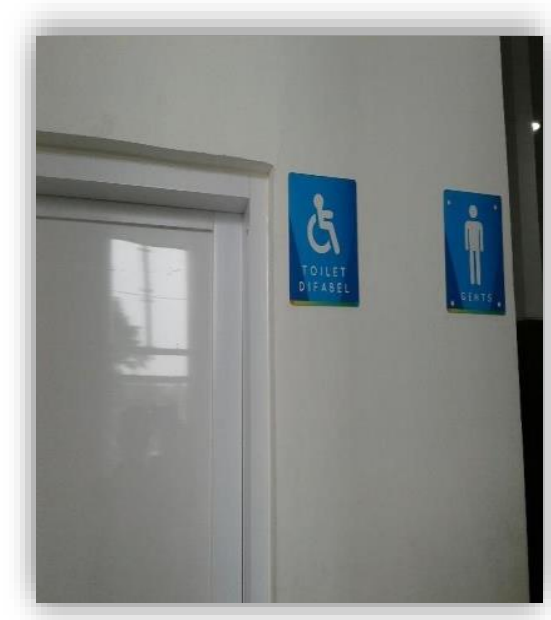

Gambar 4. Toilet Difabel

Berdasarkan poin keamanan yang tercantum dalam peraturan menteri sebagaimana mestinya bahwa fasilitas yang mencegah terjadinya tindak kriminal di Shelter terminal 3 ialah dengan adanya fasilitas CCTV, petugas kemanan yang berfungsi menjaga keamanan penumpang serta menjaga sirkulasi naik turun penumpang ataupun ketika terjadi kondisi darurat, dan tombol intercome yang digunakan oleh para pengguna jasa ketika mendapat gangguan kemanan dimana tombol berfungsi sebagai alat komunikasi yang langsung terhubung ke ruang OCC (Operating Control Centre).

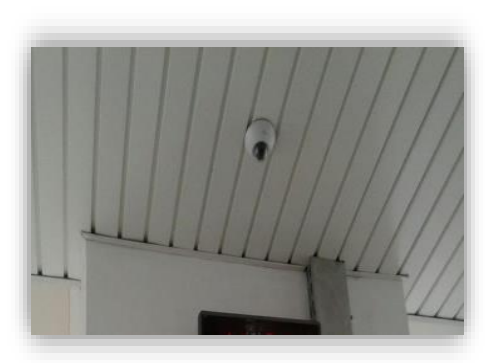

Gambar 5. CCTV

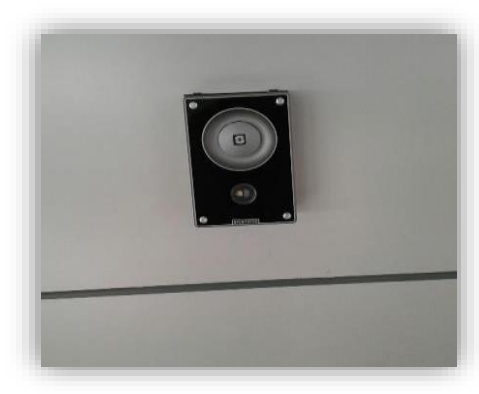

Gambar 6. Tombol Intercome

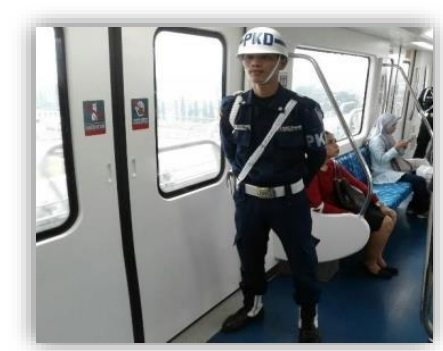

Gambar 7. Petugas Keamanan

Berdasarkan poin kemudahan ini mencakup tentang fasilitas pelayanan terkait informasi yang memudahkan para pengguna jasa dalam menerima informasi dengan mudah dan tepat. Seperti informasi terkait denah atau layout jalur terminal, petunjuk jalur evakuasi, maupun informasi visual lainnya.

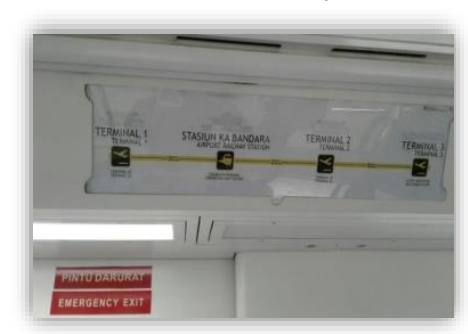

Gambar 8. Denah/layout Jalur Rute 
Airman: Jurnal Teknik dan Keselamatan Transportasi

Volume III Nomor 1 Juni 2020

P-ISSN 2622 - 0105 | E-ISSN 2716-1196

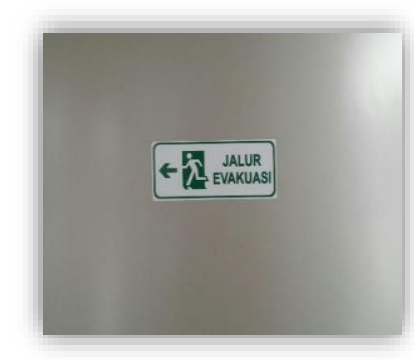

Gambar 9. Sticker Jalur Evakuasi

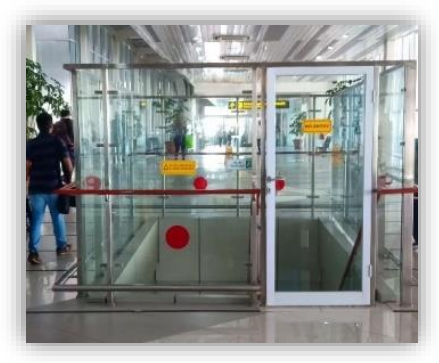

Gambar 10. Tangga Darurat

Skytrain Bandara oleh Angkasa Pura II dalam pemenuhan tingkat kenyamanan dan keamanan bagi pengguna jasa khususnya di shelter terminal 3, maka pihak penyelenggara harus menyelenggarakan sebuah sistem pengamanan penumpang terhadap kemungkinan adanya bahaya stasiun di dalam suatu kondisi darurat. Salah satu contoh kejadian yang dapat menyebabkan pengoperasian darurat yaitu kebakaran di terminal atau evakuasi sarana karena mogok yang mengharuskan dilakukannya evakuasi sebagai bentuk antisipasi dalam suatu kondisi darurat.

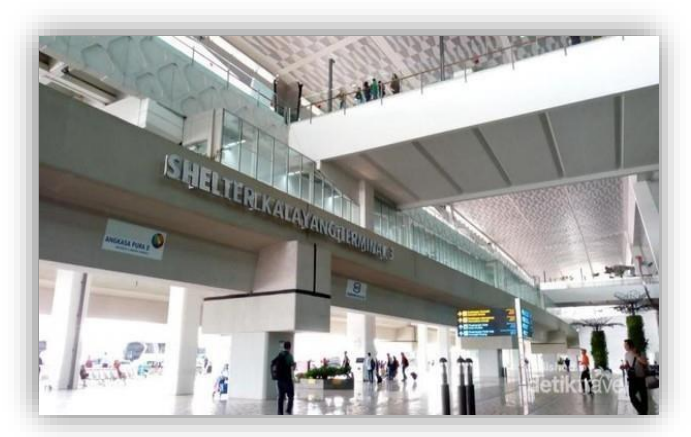

Gambar 11. Shelter Kalayang

Proses evakuasi seharusnya ditampilkan pada setiap kereta atau tempat lain yang dapat terlihat agar penumpang mengetahui apa yang harus dilakukan ketika terjadi kondisi darurat di shelter.

Prosedur evakuasi adalah: 1) Segera tinggalkan kereta ketika sesuai dengan petunjuk dari petugas evakuasi tanggap darurat atau mengikuti arah jalur evakuasi atau arah tanda keluar sampai menuju area aman, 2) Dilarang berlari, saling mendahului, dan membawa barang yang terlalu berat, 3) Turun dan keluarlah mengikutikuti tanda keluar, jangan panik, dan saling membantu untuk memastikan evakuasi selamat sampai di area aman, 4) Berkumpul di area aman yang telah ditentukan, tetap berkumpul sambil menunggu instruksi dari petugas keamanan dari Angkasa Pura II, koordinasi dengan petugas OCC (Operating Control Centre), dan petugas jaga yang sedang berdinas., 5) Koordinator lapangan segera berkondinasi dengan petugas OCC tentang tindak lanjut penumpang yang sedang dievakuasi, 6) Dilarang kembali membawa masuk ke sarana tanpa perintah langsung dari petugas yang bertanggungjawab.

Pada perhitungan di atas menunjukkan bahwa waktu untuk keluar dari concourse menuju area aman melalui eskalator ketika proses evakuasi terjadi membutuhkan waktu 2,4 menit atau 2 menit 4 detik dengan kapasitas eskalator yang tersedia di sepanjang area menuju area aman.

Tabel 1. Waktu Tunggu Keluar Melalui Eskalator

\begin{tabular}{|l|l|l|l|l|l|}
\hline $\begin{array}{l}\text { Waktu } \\
\text { Tunggu } \\
\text { Keluar } \\
\text { Eskalator }\end{array}$ & Simbol & $\begin{array}{l}\text { Waktu } \\
\text { Keluar } \\
\text { Eskalator } \\
\text { (Fes) } \\
\text { (menit) }\end{array}$ & $\begin{array}{l}\text { Waktu } \\
\text { Berjalan } \\
\text { menuju } \\
\text { Eskalator } \\
\text { (T3) } \\
\text { (menit) }\end{array}$ & $\begin{array}{l}\text { Waktu } \\
\text { Keluar } \\
\text { Platform } \\
\text { (Fpi) }\end{array}$ & $\begin{array}{l}\text { Waktu } \\
\text { Tunggu } \\
\text { (Wes) } \\
\text { (menit) }\end{array}$ \\
\hline $\begin{array}{l}\text { Waktu } \\
\text { tunggu } \\
\text { di } \\
\text { Eskalator } \\
\text { darurat } \\
\text { (Wes }\end{array}$ & Wes & 2,4 & 2,1 & 0,31 & $-0,01$ \\
$\begin{array}{l}\text { Fes } \\
- \text { T3- } \\
\text { Fpi) }\end{array}$ & & & & & \\
\hline
\end{tabular}

(Sumber data, 2019)

Dari perhitungan waktu tunggu untuk keluar menuju area aman melalui eskalator menunjukkan hasil minus (-) yakni -0,01 menit, 
hal ini menunjukkan bahwa untuk keluar menuju area aman melalui eskalatortidak ada waktu tunggu karena jumlah kapasitas dari eskalator telah memenuhi standar untuk menampung penumpang sebanyak 528 orang, sehingga tidak terjadi antrian.

Tabel 2. Total Waktu Tunggu

\begin{tabular}{|l|l|l|l|l|}
\hline $\begin{array}{l}\text { Total } \\
\text { Waktu } \\
\text { Tunggu }\end{array}$ & Simbol & $\begin{array}{l}\text { Waktu } \\
\text { Perjalanan } \\
\text { Di } \\
\text { Platform } \\
\text { (Wp) }\end{array}$ & $\begin{array}{l}\text { Waktu } \\
\text { Tunggu } \\
\text { Keluar } \\
\text { Tangga } \\
\text { Darurat } \\
\text { (Wtt) }\end{array}$ & $\begin{array}{l}\text { Waktu } \\
\text { Tunggu } \\
\text { Keluar } \\
\text { Eskalator } \\
\text { (Wtes) }\end{array}$ \\
\hline $\begin{array}{l}\text { Waktu } \\
\text { Tunggu } \\
\text { Menuju } \\
\text { Area } \\
\text { Aman }\end{array}$ & & $-0,87$ & 4,59 & $-0,01$ \\
\hline
\end{tabular}

Total Waktu Tunggu $(\mathrm{Wt}=\mathrm{Wp}+\mathrm{Wtt}+\mathrm{Wes})$ 4,11

(Sumber data, 2019)

Tabel 3. Total Waktu Evakuasi

\begin{tabular}{|c|c|c|c|}
\hline $\begin{array}{l}\text { WAKTU } \\
\text { KELUAR } \\
\text { (Platform } \\
\text { Sampai } \\
\text { Area Aman) }\end{array}$ & $\begin{array}{l}\text { Total } \\
\text { Waktu } \\
\text { Berjalan } \\
\text { (T) } \\
\text { (menit) }\end{array}$ & $\begin{array}{l}\text { Waktu } \\
\text { Tunggu } \\
\text { Total } \\
\text { Menuju } \\
\text { Area } \\
\text { Aman }\end{array}$ & $\begin{array}{l}\text { Total } \\
\text { Waktu } \\
\text { Keluar } \\
<6 \\
\text { menit }\end{array}$ \\
\hline $\begin{array}{l}\text { Total Exit } \\
\text { Time } \\
(\mathrm{T}+\mathrm{Wtp}+\mathrm{Wt})\end{array}$ & 3,25 & 4,11 & 7,36 \\
\hline
\end{tabular}

(Sumber data, 2019)

Total Waktu Evakuasi yang dapat dilakukan di Shelter Terminal 3 dengan fasilitas jalur evakuasi yang tersedia, ketika terjadi kondisi darurat membutuhkan waktu 7,36 menit. Dari hasil perhitungan waktu dengan mengasumsikan jumlah penumpang terpadat saat jam sibuk sebanyak 528 penumpang per-headway untuk dilakukannya evakuasi dari platform hingga area aman belum memenuhi standar NFPA 130 (National Fire Protection Asociation) yaitu melebihi 6 menit.

\section{KESIMPULAN}

Berdasarkan hasil analisis penulis terkait dengan efektivitas waktu evakuasi terkhusus pada Shelter Terminal 3 Bandara Internasional Soekarno-Hatta, maka didapatkan kesimpulan sebagai berikut:

1) Dari analisis yang telah dilaksanakan dapat diketahui bahwa alur penumpang ketika evakuasi dilakukan dari saat penumpang turun dari kereta pada area platform menuju pintu darurat atau melalui eskalator yang melewati automated door kemudian menuju area aman yang terdapat di ground.

2) Kapasitas penumpang dapat didapatkan dari perhitungan jumlah penumpang saat jam padat (peak hours). Perhitungan ini diperoleh dengan menghitung ratarata jumlah penumpang perhari selama 7 hari pengamatan. Sampai akhirnya didapat jumlah penumpang saat jam padat (peak hours) sebanyak 715 penumpang pada jam 13.5916.09 dan sebanyak 528 penumpang perheadway nya di jam yang sama.

Dari perhitungan total waktu evakuasi di Shelter Terminal 3 Bandara Internasional Soekarno-Hatta ketika terjadi kondisi darurat yang mengharuskan pada penumpang dievakuasi dengan asumsi jumlah penumpang terpadat saat jam sibuk sudah memenuhi standar dengan fasilitas jalur evakuasi yang tersedia seperti tangga darurat dan eskalator, dengan maksimal waktu evakuasi dari ketika penumpang keluar platform sampai menuju concourse (area terbuka) yaitu 0,43 menit. Area concourse yang tersedia di area shelter sekaligus merupakan area tunggu.

Skytrain (kereta layang) memiliki platform yang khusus untuk naik turun penumpang sehingga hanya membutuhkan waktu singkat untuk menuju area terbuka yang merupakan area ketika penumpang sudah keluar dari kereta dan dari perhitungan total waktu evakuasi di Shelter Terminal 3 Bandara Internasional SoekarnoHatta dengan perhitungan waktu maksimal untuk evakuasi dari penumpang keluar platform sampai menuju area aman yang didapat yaitu 7,36 menit. Sehingga waktu evakuasi tersebut belum memenuhi standar NFPA 130 (National Fire Protection Asociation) yaitu maksimal 6 menit. 


\section{DAFTAR PUSTAKA}

American National Standard. (2007). NFPA 130. Tentang Standard for Fixed Guideway Transit and Passegers Rail Systems. Amerika: 2014

Angkasa Pura

II.

https://www.angkasapura2.co.id/, tanggal 26 Januari 2019.

Ningbo CONAI. $\quad \underline{\text { htp://id.elevator- }}$ cn.com/company-honor/, Tahun 2004.

OSHA. 2003. Emergency Exit Routes, U.S. Departement of Labirm Washington.

Pemerintah Republik Indonesia. (2007). Undang-undang Nomor 23 Tahun 2007 tentang. Perkeretaapian. Jakarta: Sekertariat Negara Republik Indonesia.

Pemerintah Republik Indonesia. (2010). Peraturan Kepala Badan Nasional Penanggulangan Bencana Nomor 13 Tahun 2010 Tentang Pedoman Pencarian, Pertolongan Dan Evakuasi.

Pemerintah Republik Indonesia. (2015). Peraturan Menteri Nomor 24 Tahun 2015 tentang Standar Keselamatan Perkeretaapian. Jakarta: Menteri Perhubungan Republik Indonesia.

Pemerintah Republik Indonesia. (2015). Peraturan Menteri Nomor 48 Tahun 2015 tentang Standar Pelayanan Minimum Angkutan Orang Dengan Kereta Api. Jakarta: Menteri Perhubungan Republik Indonesia

Pemerintah Republik Indonesia. (2015). Peraturan Menteri Nomor 69 Tahun 2018 tentang Sistem Manajemen Keselamatan Perkereteaapian. Jakarta: Menteri Perhubungan Republik Indonesia.

Pynkyawati, T., Wahadamaputera, S., Adiwibowo, F., Lestari, R., Septaningsih, D. (2009) Kajian Desain Sirkulasi Ruang Dalam sebagai Sarana Evakuasi Kebakaran pada Bangunan
Hotel Carrcadin Bandung, Jurnal Teknologi, Bandung.

S. Anvari, S, Tune, M. Canci, and M. Turkay. (2012). "Automated Boc-Jenkins frecasting tool with an application for passenger deman in urban rail systems," Journal od Advanced Transportasion, vol. 50, no. 1, pp 1148-162.

Y, Zheng. (2011). "Analysis on passenger trip mode split of Beijing subway,".Journal of Transportasion Systems Engineering and Information Thechnology, vol. 11, no. 3, pp. 163-168, 2011. 